\title{
IMPORTACIONES E IMITACIONES DE CERÁMICA ROMANA EN EL YACIMIENTO DE CERCADILLA (CÓRDOBA) SIGLOS I AL III D.C.
}

Maudilio MORENO ALMENARA

\section{Resumen}

Presentamos en este trabajo algunos de los materiales cerámicos recuperados en las excavaciones realizadas en el yacimiento de Cercadilla durante 1991 y 1992 . El marco cronológico está comprendido entre el siglo I-III d.C., adscribiéndose, por tanto, a los niveles subyacentes al gran palacio tardorromano de Maximiano Hercúleo. Dada la importancia del fenómeno de las imitaciones de cerámica importada en Cercadilla hemos preferido en este trabajo analizar fundamentalmente las importaciones de cerámica de cocina y mesa y sus imitaciones.

\section{Summary}

We introduce in this paper a set of roman pottery from the archaeological excavations undertake at Cercadilla's site during 1991 and 1992. The chronology of these materials covers the 1 st and 3rd centuries A. D., being earlier than Maximiano Herculeo's palace. The local imitations of imported pottery are an important phenomenon at Cercadilla, so we have preferred in this paper to analyse only the imports of kitchen and red slipware and their imitations.

\section{Introducción}

Los materiales cerámicos aquí presentados ${ }^{i}$ forman parte del estudio que hemos realizado para nuestra Memoria de Licenciatura ${ }^{2}$. El conjunto es muy variado y se

\footnotetext{
' El material gráfico que se incluye en este trabajo ha sido realizado por Da Marina L. González Vírseda a la que desde aquí queremos mostrar nuestro más sincero agradecimiento.

${ }^{2}$ Esta Memoria de Licenciatura, con el título: La villa suburbana de Cercadilla. Análisis arqueológico fue presentada en el mes de Diciembre de 1997 en la Universidad de Córdoba, bajo la dirección del Prof. Dr. Desiderio Vaquerizo Gil.
} 
corresponde con los niveles subyacentes al palacio tardorromano de Cercadilla ${ }^{3}$. Se asocian en general a las distintas fases de una villa suburbana que se localizó bajo el gran patio o espacio abierto que enmarca el criptopórtico del palacio, constituyendo una buena muestra, muy significativa en cuanto, a su aportación como idea general del fenómeno de las importaciones y sus imitaciones en la Colonia Patricia.

\section{Cerámica itálica de cocina}

Son muy escasos los testimonios sobre esta producción recuperados en Cercadilla. Básicamente debemos asociarla a niveles augusteos con perduraciones durante la primera mitad del siglo I d.C. Las formas representadas son: Tapaderas del tipo Celsa 80. 8145 (SÁNCHEZ, 1995, fig. 10.24) y platos de la forma Luni 5 (Aguarod 6/ Oberaden 21 a y b/Vegas 15c/Haltern $75 \mathrm{~A}$ ). Ambos tipos muestran pastas similares a las del grupo 2 de la Tarraconense (AGUAROD, 1991, 52) con origen en la Campania.

En Córdoba contamos con algunos otros datos sobre esta producción si bien no conforman aún una muestra amplia. Así, se conoce la presencia de sartenes del tipo Celsa 84.13596 en los niveles del Templo romano de la C/ Claudio Marcelo (SÁNCHEZ, 1995, 257). De la capital cordobesa procede asimismo un plato de engobe interior rojo pompeyano con un diámetro cercano a los $70 \mathrm{~cm}$ (IBID., 1995, 259), tapaderas de borde recto (IBID., 1995, 263) y morteros del tipo Dramont D2 (IBID., 1995, 267).

\section{Terra sigillata itálica}

La terra sigillata itálica constituye la primera de las producciones de la gran familia denominada genéricamente sigillata. Comprende momentos cronológicos establecidos, grosso modo, entre mediados del siglo I a.C. y los años 60/80 d. C (ROCA, 1982, 364 y 368).

\footnotetext{
${ }^{3}$ En estos momentos disponemos de una amplia bibliografía sobre este gran yacimiento de la capital cordobesa. Por no ser demasiado exhaustivos citaremos tan sólo las tres monografías disponibles:

HIDALGO PRIETO, R. (1996): Espacio público y espacio privado en el conjunto palatino de Cercadilla (Córdoba). El Aula Central y las Termas. Sevilla.
}

HIDALGO ET ALII (1996): El criptopórtico de Cercadilla. Análisis arqueológico y secuencia estratigráfica. Sevilla.

MORENO ALMĖNARA, M. (1997): La villa suburbana de Cercadilla (Córdoba). Análisis arqueológico. Sevilla. 
La vida de este tipo de cerámica abarca diversas fases, la primera de ellas ocupa unos veinte años (50/45-30/25 a.C.) en los que se llevan a cabo ensayos tendentes a depurar cuestiones técnicas ${ }^{4}$. Las series fabricadas en estos momentos, y que a veces presentan irregularidades como la combinación de color rojo y negro o barnices muy oscuros, se enmarcan en la denominada prearetina ${ }^{5}$.

Los primeros testimonios de sigillata itálica en Cercadilla muestran marcas radiales y origen en Arezzo, con una cronología comprendida el 30 y el 15 a.C. Contamos también con la presencia de los tipos Conspectus 4, 12, 14 y 15, estas formas están igualmente presentes en los conjuntos recuperados en el templo romano y el exconvento de la Merced.

La siguiente etapa es la comprendida entre el 15 a.C. y el cambio de Era, aunque algunas de las formas muestran perduraciones hasta el principado de Tiberio. En este periodo se observa una mayor variedad formal en la sigillata itálica recuperada en Cercadilla, marcada por la presencia de las formas Conspectus 18, 19, 22, 31 y 32 . Encuadrable en parte en este lapsus temporal, el mejor testimonio lo tenemos en Córdoba en el conjunto hallado en el exconvento de la Merced.

Se comprueba que la mayor parte de las importaciones de sigillata itálica se corresponden en este momento con productos de Arezzo, aunque también existen ejemplares que proceden de otros talleres. Se trata del momento álgido de las importaciones itálicas.

Tras la fase clásica de la sigillata itálica continua hasta los años $35 / 40$ d.C. la fase avanzada. En este momento contamos con la información que se desprende de los conjuntos cerámicos del Templo romano. En ellos se observa la presencia de las formas Conspectus 9, 20, 25, 26, 33, 38 y 50. Al final de esta fase comienza la competencia con la terra sigillata gálica. En Cercadilla sólo contamos para este periodo con un fragmento de borde del tipo Conspectus 20.

A partir del 40 d.C. comienza la última fase de la sigillata itálica, una etapa para la que se conocen pocas piezas en Cercadilla. Están presentes las formas Conspectus 29 y 34 .

En cuanto a los alfareros, en Cercadilla se han recuperado varios sigilla y fragmentos de sigilla. El primero de ellos se corresponde con C. SERTORIVS sobre una base

\footnotetext{
${ }^{4}$ No olvidemos que la sigillata procede de la cerámica de barniz negro, con lo que se produce una transformación en la cocción para conseguir el "nuevo" color rojo.

${ }^{5}$ La identificación de la prearetina como material perteneciente a una época en la que se lleva a cabo la puesta a punto de la nueva técnica empleada en la fabricación de la sigillata fue demostrada hace tiempo por Goudineau (ROCA, 1982, 359).
} 
decorada a ruedecilla, posiblemente del tipo Conspectus 1 ó 4. Esta marca con disposición radial puede pertenecer a C. SERTORIVS PROCVLVS 6 , de Arezzo (BELTRÁN, 1990, 72), o bien C. SERTORIVS OCELLA (OXÉ y COMFORT, 1968, 422-423).

La segunda de las marcas aparece sobre el fondo de una posible copa del tipo Conspectus 22. Se trata de la inscripción ATEII, que pertenece a CN. ATEIVS ${ }^{7}$ de Arezzo (BELTRÁN, 1990, 68).

El tercero de los sigilla recuperados en Cercadilla se corresponde con la marca PRO. ANII $^{8}$-cuya procedencia desconocemos-, mientras que el cuarto presenta la inscripción HORVS P. COR. ${ }^{9}$, posiblemente del alfarero de Arezzo P. CORNELIVS ${ }^{10}$ (BELTRÁN, $1990,65)$ que en este caso debe firmar con el esclavo HORVS, en asociación similar a la que se observa con el alfarero RASINIVS ${ }^{11}$ (BELTRÁN, 1990, 66).

La última marca aparece sobre el fondo de una posible copa del tipo Conspectus 22. Se conservan las dos primeras letras de dicho sigillum PR... (IMVS) ${ }^{12}$, del valle del Po (BELTRÁN, 1990, 72).

\section{Terra sigillata gálica}

Se denomina sigillata gálica a aquella producción centrada en diversos talleres de la Galia, con actividad en parte contemporánea a la sigillata aretina pero que sobrevive a ésta (ROCA, 1982, 374).

El conjunto de materiales pertenecientes a esta producción que ha sido documentado en Cercadilla es escaso, siendo también el repertorio formal más reducido que en el caso de la sigillata itálica. Se han recuperado piezas correspondientes a los tipos Drag. $15 / 17,18,24 / 25,27,29,36,72$, Ritterling 8 y $9^{13}$.

${ }^{6} \mathrm{~N}^{\circ} 1781 / 1783$ (OXÉ y COMFORT, 1968, 423-424).

${ }^{7}$ Se conocen numerosas marcas de este alfarero o alfareros ( $\mathrm{n}^{\circ}$ 144-186) (OXÉ y COMFORT, 1968, 42).

${ }^{8} n^{\circ} 4.3020$. Debe corresponderse con el alfarero ANNIVS de Arezzo ( $n^{\circ} 77$ y ss.) (OXÉ y COMFORT, 1968, 15)

${ }^{9}$ Sector $16 /$ termas.

${ }^{10} \mathrm{~N}^{\circ} 471$ y ss. (OXÉ y COMFORT, 1968, 154).

${ }^{11}$ De Córdoba, aunque desconocemos el lugar concreto (posiblemente el Templo de la C/ Claudio Marcelo), procede un fragmento decorado con una cenefa de ovas y flechas y bajo ella una figura masculina alada (genio) junto a una palmeta vertical, muestra la marca intradecorativa RASIN del alfarero RASINIVS (BALIL, 1978, 413-414).

${ }^{12}$ No 1398 (ӨXÉ y COMFORT, 1968, 347).

${ }^{13}$ Se trata en este caso de una marmorata. 
Entre las piezas decoradas destaca una Drag. 30 ornada con ovas y flechas a modo de cenefa en la parte superior del campo decorativo. Como motivo central se disponen elementos vegetales -adormideras- muy similares a otros conocidos del grupo de la Graufesenque (D.A.F., 1986, 101). Además nos resta un fragmento perteneciente a una forma cerrada de perfil más o menos globular que se adorna con un motivo heráldico característico de naturaleza vegetal. Este esquema está representado en el grupo de Montans (D.A.F., 1986, 88).

Se conservan también otros cuatro fragmentos decorados. El primero de ellos pertenece al friso inferior de una pieza, realizado mediante motivos vegetales de adormideras dispuestas en racimos de tres flores en los que la central conecta con la base del siguiente racimo. Este esquema es muy característico del grupo de la Graufesenque (D.A.F., 1986, 66).

Otros dos fragmentos muestran motivos muy similares en los que se disponen círculos concéntricos con incisiones. La conservación de estos fragmentos es muy deficiente. En ambos casos las representaciones pueden asimilarse a otras constatadas en el taller de Montans (D.A.F., 1986, 66).

El último de estos fragmentos es un pequeño galbo en el que se representa un ave que vuelve la cabeza hacia atrás, se inscribe en un semicírculo. Estos motivos existen en el taller de la Graufesenque (D.A.F., 1986, 105).

En cuanto a los sigilla, hemos identificado cinco: se trata de las marcas OF LVCCE(IVS) de la Graufesenque, cuya producción se centra en época flavia (OSWALD, 1931, 168-169), CRIS(PVS) de la Graufesenque y Montans, cuya actividad oscila entre los principados de Claudio y Domiciano (OSWALD, 1931, 97), FELIX SEV(ERVS), se corresponde con los alfareros FELIX y SEVERVS de la Graufesenque, cuya producción se sitúa entre época de Claudio y Vespasiano (OSWALD, 1931, 121), OF SA(BINVS $)^{14}$ de la Graufesenque y Montans, que abarca los principados de Nerón a Domiciano (OSWALD, 1931, 272-273) y EXO...IL, que puede pertenecer al alfarero OCELLVS del sur de la Galia (OSWALD, 1931, 223).

Los únicos datos estratigráficamente fiables disponibles ${ }^{15}$ en Córdoba ${ }^{16}$ son por el momento los que se desprenden de algunos niveles de la cella del Templo romano, con una cronología centrada en el principado de Tiberio o inicios del de Claudio,

\footnotetext{
${ }^{14}$ Del tipo in planta pedis

${ }^{15}$ Nos referimos a datos publicados y que contengan una muestra más o menos amplia, con asociaciones que nos permitan analizar esta producción desde un punto de vista cronológico..

${ }^{16}$ También contamos con el vertedero B de Orive, donde se localizó un conjunto formado principalmente por sigillata gálica aunque está pendiente de publicación definitiva.
} 
constatándose una tímida presencia de sigillata gálica $-1.4 \%$-, frente al $18.5 \%$ de itálica (JIMÉNEZ, 1996, 136).

Vemos por tanto cómo la llegada de estos productos tiene su inicio en Córdoba, grosso modo, en tiempos del emperador Claudio. La época de auge debe coincidir con la importación masiva principalmente de productos de La Graufesenque durante época de Nerón y los primeros emperadores de la dinastía flavia. A partir de este momento los productos hispánicos deben en buena medida competir con la sigillata gálica acaparando paulatinamente el mercado de la Colonia Patricia.

\section{Terra sigillata hispánica}

En Cercadilla observamos un número elevado de productos de Andújar, tanto si lo comparamos con la cerámica de los alfares riojanos como con la sigillata gálica e itálica.

Los sigilla localizados en Cercadilla muestran la presencia de algunas de las principales marcas de aquellos talleres, lo que refrenda algo que era fácilmente intuible: que los productos de Andújar debieron llegar de manera masiva a la capital de la Bética. Entre ellos destacan: EXOVD (SOTOMAYOR, 1972, 272), EXOIC (IBID., 1972, 270), EXOP (IBID., 1972, 276), MSM (IBID., 1972, 276), EXOAA (IBID., 1972,274 ) y OTO, probablemente TITI OPPI ${ }^{17}$ (SOTOMAYOR, PÉREZ y ROCA, 1976, 118). El inicio en el flujo de sigillata de Andújar debe ser relativamente temprano, aunque en ningún caso nos parece anterior a época de Claudio, pues no aparecen en la cella del templo romano de la C/ Claudio Marcelo (JIMÉNEZ, 1996, 129153). En Cercadilla no obstante, se ha recuperado un sello con la marca MSM, alfarero del taller de Andújar cuya producción se centra en época de Claudio (ROCA, 1981, 407). A partir de este momento debe ir creciendo de manera paulatina la llegada de sigillata de Andújar aunque con la fuerte competencia de los productos galos. No obstante, deben ganarle la partida sobre todo a partir de la segunda mitad del siglo I d.C. Los porcentajes de sigillata de Andújar habrán de ser mayoritarios ya durante la primera mitad del siglo II d.C. para llegar, aún en proporciones elevadas al tercer cuarto de dicha centuria, sufriendo en estos momentos la competencia de la sigillata africana de mesa (CARRILLO y MURILLO, 1996, 1316-1317) según se desprende de los datos recuperados en el vertedero A de Orive.

${ }^{17}$ Quizás podría interpretarse como O(F) T(ITTIVS) O(PIVS), aunque la marca normal de este alfarero es TITI OPPI. 
Las formas presentes en el yacimiento de Cercadilla son las siguientes: Hispánica 4, Drag. 15/17, 24/25, 27, 29/37, 29, 37, Hermet 13, Mezquiriz 70 y una pieza ciertamente extraña, muy similar al tipo Conspectus 32 .

En cuanto a las piezas decoradas, contamos con dos ejemplares del tipo Drag. 29. Ambos muestran metopas separadas con las típicas series de líneas onduladas verticales que enmarcan bifoliáceas. En las metopas se insertan en un caso una esfinge rampante junto a una palmera y en el otro un perro o liebre corriendo (ROCA, 1976, 97). También hay tres piezas correspondientes al tipo Drag. 29/37. En este caso existe una mayor variedad ya que la primera de las piezas muestra una decoración de hojas, la segunda una serie de círculos que enmarcan a su vez otro círculo más pequeño (ROCA, 1976, similar a fig. $43, \mathrm{n}^{\circ} 222$ ) y la tercera conserva tres metopas, los motivos incluidos en ellas son un perro corriendo, un cérvido y un conejo en reposo (ROCA, 1976, 97). Por último, se han recuperado cinco cuencos del tipo Drag. 37 , dos con decoración a ruedecilla y tres más a molde. Uno alterna los círculos en la franja superior, separados por bastones con adormideras en los extremos (ROCA, 1976, similar a fig. 52, $\mathrm{n}^{\circ}$ 511, aunque en posición invertida) con decoración de metopas en la inferior, flanquedas por las típicas líneas onduladas. Hemos identificado los motivos de dos de las metopas, uno de ellos una hoja (ROCA, 1976, similar a fig. 51, $\mathrm{n}^{\circ}$ 456-457), y el otro parece representar un personaje alado. Un segundo ejemplar muestra círculos tanto en la franja superior como en la inferior. En la franja superior los círculos incluyen una hoja (ROCA, 1976, similar a fig. 46, $\mathrm{n}^{\circ} 330$ ), mientras que en la inferior enmarcan otro círculo más pequeño (ROCA, 1976, similar a fig. 44, n 240). La decoración de la tercera pieza parece consistir en series de círculos enlazados (ROCA, 1976, fig. 50, 410-411).

No hemos encontrado productos claramente asimilables a otros talleres béticos.

La sigillata hispánica procedente de los alfares riojanos es escasa en Cercadilla. Encontramos sólo la marca OF SEM que se corresponde con el alfarero SEMPRONIVS $^{18}$ de Tricio $^{19}$ (BELTRÁN, 1990, 115). También se conservan dos formas decoradas, destacando un ejemplar del tipo Drag. 30 con amplias metopas enmarcadas por series de líneas onduladas que encuadran una línea vertical de bifoliáceas. La metopa muestra un dibujo muy delicado con una hoja, bajo ésta se dispone una línea horizontal de bifoliáceas y una varilla rematada en forma de abani-

${ }^{18} \mathrm{~N}^{\mathrm{o}} 272$ (ATLANTE II, 1985, 137).

${ }^{19}$ La marca OF SEM también puede identificarse con el alfarero SEMPER del Sur de la Galia (OSWALD. 1931, 291), aunque en este caso las características formales de la pieza nos hacen inclinarnos hacia SEMPRONIVS. 
co. Sobre la metopa se observa una finísima serie de ovas. La otra pieza se corresponde con una forma cerrada no tipificable, hacia el exterior se decora con metopas enmarcadas por series de cuatro líneas onduladas. En las metopas se repite un motivo no identificado aunque podría ser algún tipo de ave, y bajo él un jarro -urceus-.

Estos productos son poco frecuentes en Córdoba aunque está documentada su presencia, que debe corresponder a momentos en los que aún no están bien definidas las redes comerciales propias de la sigillata de Andújar. Deben ser, por tanto, productos que habrían acompañado en su llegada a Córdoba a las producciones galas, especialmente durante la segunda mitad del siglo I d.C.

\section{Cerámica de barniz rojo tipo Peñaflor}

Martínez Rodríguez establece tres grupos para estas imitaciones: el primero que imita a copas y páteras de sigillata gálica e itálica, el segundo que sigue modelos de alguna variante tardía de fuentes de barniz rojo pompeyano y el último que imita boles y tazas en paredes finas (MARTíNEZ, 1989, 60). Vemos por tanto que el hilo conductor de esta producción es la imitación de determinados productos importados de los siglos I a.C./ I d.C.

El repertorio formal de imitaciones tipo Peñaflor recuperado en Cercadilla es bastante amplio y constituye una prueba de su presencia abundante en la Colonia Patricia durante los años centrales del siglo I d.C. Se han recuperado ejemplares clasificados dentro de la tipología de Martínez Rodríguez (1989) como pertenecientes al subtipo Ib, Ic, Id, IIc, IIIa, IIIb, IV y un nuevo tipo, denominado por nosotros forma V, que muy probablemente imita al tipo Goudineau 21(Conspectus 36) en Terra Sigillata Itálica.

Hay dos formas que preponderan en el yacimiento, el subtipo Ib, es decir, las imitaciones de fuentes de barniz rojo pompeyano y el tipo $\mathrm{V}$, descrito anteriormente (vid. supra). Las cronologías son relativamente amplias, abarcando desde época de Augusto hasta principios del s. II d.C. ${ }^{20} \mathrm{El}$ momento álgido de la producción en Cercadilla habría que situarlo a partir del primer tercio del s. I d.C., coincidente en buena medida con las últimas importaciones de sigillata itálica a Córdoba y sobre todo con la sigillata gálica.

\footnotetext{
${ }^{20}$ En el vertedero A de Orive, los porcentajes de esta familia cerámica son muy bajos, tratándose de materiales residuales. La cronología de este vertedero es la segunda mitad del siglo II d. C. (CARRILLO y MURILLO, 1996, 1303) aunque nos da una prueba muy sólida de que la cerámica de barniz rojo tipo Peñaflor, si llega hasta el siglo II d. C. debe ser en porcentajes muy minoritarios. Los datos más fiables, aún no suficientemente contrastados, parecen indicar que al menos en Córdoba esta producción coincide en buena medida con la presencia de la Terra Sigillata Gálica en la capital de la Bética.
} 
Los ejemplares de Cercadilla no están en ningún caso decorados, aunque en Córdoba se conocen algunas piezas que sí lo están, tal es el caso de un ejemplar del templo romano de la C/ Claudio Marcelo que presenta cuatro estampillas con motivo vegetal dispuestas en el fondo (JIMÉNEZ, RUIZ y MORENO, 1996, 120).

No descartamos que esta producción pueda dar ciertas sorpresas en Córdoba, pues es ciertamente significativo que en Cercadilla se haya encontrado al menos una forma no recogida en las tipologías conocidas hasta el presente ${ }^{21}$.

\section{Terra sigillata africana A}

La terra sigillata africana A se divide, grosso modo, en dos subproducciones $\left(\mathrm{A}^{1}\right.$ y $\left.\mathrm{A}^{2}\right)^{22}$ con diferencias no sólo en el barniz sino también a nivel formal, predominando en la africana $\mathrm{A}^{2}$-más tardía- las formas abiertas, exvasadas, lisas y en general sencillas, mientras que en la $\mathrm{A}^{1}$ son más frecuentes los cuencos y boles -decorados o lisos- así como las jarras y botellas ${ }^{23}$.

\section{Formas tempranas}

La subproducción $\mathrm{A}^{1}$ está representada en el yacimiento de Cercadilla por las formas Hayes 3b, 3c, 6b, 8a, 8b, 9a, 9b y 160. Predominan las formas abiertas, cuencos principalmente, aunque también existen dos pequeños fragmentos pertenecientes a la inflexión en la pared de dos botellas de la forma Hayes 160.

Para la producción $\mathrm{A}^{\mathbf{1}}$ contamos en Córdoba con la inestimable información proporcionada por la excavación de un vertedero de cerámica en el palacio de Orive (CARRILLO y MURILLO, 1996, 1301-1319). Los porcentajes de esta producción son en este vertedero del $1.1 \%$ de la totalidad de cerámica recogida. La convivencia con la última facies de la terra sigillata hispánica de Andújar, con porcentajes mucho más elevados, nos permite suponer un momento relativamente tardío para la introducción de la producción A en Córdoba. La fecha asignada a dicho vertedero se

${ }^{21}$ Tenemos noticia de la presencia de materiales inéditos con otras formas no tipificadas y con algún posible sello de alfarero.

${ }^{22}$ Existe una subproducción intermedia entre la $\mathrm{A}^{1}$ y $\mathrm{A}^{2}$, denominada $\mathrm{A}^{1 / 2}$, aunque en nuestra clasificación hemos atendido más a criterios tipológicos que a los propios de subproducciones.

${ }^{23}$ Las formas abiertas tardías están fabricadas en $\mathrm{A}^{2}$, siendo por tanto más clara su adscripción. En el caso de las formas tempranas, la cuestión es más compleja, pues la mayor parte de los tipos se fabrican tanto en $\mathrm{A}^{1}$ como en $\mathrm{A}^{2}$, así como en $\mathrm{A}^{1 / 2}$, por lo que de modo muy general, y atendido más a una cuestión cronológica y formal se ha subdivido en dos apartados incluyendo el primero aquellas formas que aunque se fabriquen igualmente en $\mathrm{A}^{1 / 2}$ y $\mathrm{A}^{2}$, lo hacen también en $\mathrm{A}^{1}$, mientras que las incluidas en el segundo grupo sólo están producidas en $\mathrm{A}^{2}$. 
estima entre el 150 y 175 d.C., observándose por tanto la tímida introducción de estos primeros productos africanos de cerámica de mesa.

En cualquier caso es significativa la aparición de un tintero del tipo Hayes 124 (Lamboglia 16bis), forma poco frecuente, lo que de alguna manera demuestra, junto con los altos porcentajes de africana de cocina, que no debieron existir grandes dificultades para la llegada de productos africanos a Córdoba y que la escasa entidad del volumen de producción $\mathrm{A}^{1}$ se debería más a la competencia con la terra sigillata hispánica de Andújar que a otras circunstancias.

En resumen, destacaríamos un momento inicial tímido coincidente en buena medida con el último momento de la sigillata hispánica de Andújar. Ello se manifiesta en la llegada de algunos productos de forma más o menos aislada, probablemente desde época antoniniana temprana, materializada de forma especial en los cuencos del tipo Hayes 3 b-c (HAYES, 1972, 25).

A partir ya de mediados del siglo II d.C. ${ }^{24}$ las importaciones de sigillata africana comienzan a crecer, correspondiendo a este segundo momento la llegada de cuencos del tipo Hayes 8, con una cronología centrada en el siglo II d.C. (HAYES, 1972, 35), y los cuencos del tipo Hayes $6 \mathrm{~b}$, con una fecha de fabricación que comprende la segunda mitad del siglo II d.C. (HAYES, 1972, 31) y más frecuente el tipo Hayes 9, especialmente en la versión decorada a ruedecilla, con una cronología muy similar al del tipo Hayes 8 aunque con un inicio algo posterior (HAYES, 1972, 37).

\section{Formas tardías}

En Córdoba -a partir del momento álgido observado con la subproducción $\mathrm{A}^{1}$ a mediados del s. II d.C.- se comprueba una caída de las importaciones de africana de mesa, sobre todo en el último cuarto del siglo II d.C., con una timidísima aparición de la subproducción $\mathrm{A}^{2}$, especialmente observable en la forma Hayes 16. En Cercadilla están presentes las formas Hayes $14 \mathrm{~b}$ y 16 que muestran una cronología similar centrada en la segunda mitad del siglo II d.C. con algunas perduraciones (HAYES, 1972, 41-42).

\footnotetext{
${ }^{24}$ Los porcentajes observables en el vertedero A de Orive, aunque no espectaculares, sí que constituyen un claro ejemplo de la llegada de estos productos a Córdoba, así, la presencia de sigillata de Andújar es del $10.87 \%$ frente al $1.32 \%$ de africana A (CARRILLO y MURILLO, 1996) indica la gran pervivencia de los productos hispánicos de mesa en un momento avanzado para esta producción (ROCA, 1976, 106) ya que su cantidad en este caso es ocho veces mayor.
} 


\section{Terra sigillata africana $\mathbf{A} / \mathbf{D}$}

Es muy escasa la presencia de la sigillata africana A/D en el yacimiento. Sobre la aparición de esta producción en Corduba sólo contamos con la noticia de la presencia de un fragmento de fuente del tipo Hayes 27 (ALONSO de la SIERRA, 1995, 150).

La africana A/D continua a la africana A siendo muy escasa su presencia en el yacimiento de Cercadilla y por extensión, a tenor de lo publicado, en toda la Colonia Patricia. Las formas localizadas son los platos Hayes 27 -fabricados también en $\mathrm{A}^{2}$ con una cronología comprendida entre los años 160 y 220 d.C. (HAYES, 1972, 51) y Hayes 31, con fabricación entre el 200 y el 250 d.C. (HAYES, 1972, 53). La banda cronológica coincidiría con el periodo comprendido entre los años 175 y 225 d.C.

\section{Terra sigillata africana $\mathrm{C}$}

La africana $\mathrm{C}$ es de las distintas producciones de sigillata africana la más frecuente en número dentro del yacimiento de Cercadilla. Supone también su momento álgido, con una variedad formal importante aunque desigualmente representada en sus tipos. Están presentes las formas Hayes 44, 45, 46, 48, 49, 50a, 52b y 73a y b. El que con mayor número se ha documentado es el tipo Hayes 50 en su variante " $a$ ", la gran mayoría corresponden a la subproducción $\mathrm{C}^{\mathbf{l}}$ siendo en pocas ocasiones fragmentos pertenecientes a la subproducción $\mathrm{C}^{2}$. El segundo tipo más frecuente es la forma Hayes 44 .

La producción $\mathrm{C}^{3}$ está representada por los tipos Hayes 73a y 73b. Fueron recuperadas, no obstante, en estratos pertenecientes a fases de ocupación del palacio tardorromano por lo que de alguna manera quedan fuera de nuestro ámbito de estudio.

La amplia banda cronológica de esta producción que abarca desde el año 220 d.C. para el tipo Hayes 44 (ATLANTE I, 1981, 70) al 475 d.C. para las piezas más tardías del tipo Hayes 73 (IBID., 1981, 72) no deben enmascarar una serie de altibajos comerciales más que probables en este extenso periodo. Es significativa la presencia de la subproducción $\mathrm{C}^{\mathbf{1}}$ frente a la $\mathrm{C}^{2}$, y sobre todo la abundancia de sus imitaciones. Estos hechos parecen indicar un primer momento álgido ${ }^{25}$ de la importación de la sigillata africana $\mathrm{C}$ a mediados del siglo III d.C., al que debe seguir un descenso más o menos brusco y un auge de las imitaciones en la segunda mitad de la centuria. Aunque faltan grandes depósitos de material cerámico del siglo IV d.C. en Cercadilla, parece que el panorama se extiende hasta el segundo cuarto de dicho siglo, momento en el que vuelven a llegar productos africanos, en este caso de la subproducción $\mathrm{D}^{\mathbf{1}}$.

\footnotetext{
${ }^{25}$ Este posible momento álgido no está exento de matizaciones (ALONSO de la SIERRA, 1995, 159).
} 


\section{Cerámica africana de cocina}

En el yacimiento de Cercadilla el fenómeno de las importaciones de africana de cocina es de gran interés por lo que parece desprenderse de la presencia y ausencia de determinados tipos. Se han recuperado piezas pertenecientes a los tipos Hayes 23a y b, 181, 182, 194, 196 y 197. Las formas más numerosas son las cazuelas Hayes 23b con borde redondeado y las cacerolas de borde aplicado Hayes 197 y algo menor es el número de piezas pertenecientes al tipo Hayes 181. Este fenómeno es similar al que se documenta en el vertedero de Orive.

El tipo Hayes 23a, típico de la facies flavia y por tanto algo anterior a las otras formas mencionadas, sólo está documentado en Cercadilla a través de dos ejemplares. La forma Hayes 194, de la que se ha recuperado un único ejemplar en Cercadilla, muestra una cronología que puede encuadrarse también dentro de la facies flavia (ATLANTE I, 1981, 216).

De todo ello se deduce la presencia relativamente tardía ${ }^{26}$ de importaciones de africana de cocina en Colonia Patricia, sólo documentada de una forma clara a partir de la mitad del s. II d.C. También parece intuirse la presencia masiva de imitaciones durante el siglo III d.C. en menoscabo de las importaciones.

\section{Imitaciones de cerámica africana de cocina ${ }^{27}$}

El fenómeno de las imitaciones de africana de cocina está constatado en la Península Ibérica, sobre todo en la Tarraconense.

En la Bética debe tener igualmente una amplia difusión e importancia, así se conoce la presencia de imitaciones de africana de cocina en el Bajo Guadalquivir en Mulva, Orippo e Itálica (Sevilla), entre las formas más representativas destacan las tapaderas Ostia I, 261 (HAYES 196), Ostia III, fig. 332, las fuentes o escudillas tipos Hayes 181 y las cazuelas tipo Hayes 23 a y b y Hayes 197 (SÁNCHEZ, 1995, 267).

De este grupo de imitaciones cabría valorar dos aspectos fundamentales: el primero la interpretación del fenómeno en sí, y el segundo las consideraciones cronológicas que pudieran intuirse ${ }^{28}$.

\footnotetext{
${ }^{26}$ No obstante existen datos que indican la presencia de africana de cocina en Córdoba a partir de inicios del siglo II d. C. aunque posiblemente de forma esporádica -es escasísimo el número de piezas que pueden adscribirse a estos momentos-. Estos datos se desprenden de las cronologías aplicadas a los tipos Hayes 23a y Hayes 194, ambos presentes en el yacimiento de Cercadilla.

${ }^{27}$ El conjunto de materiales de Cercadilla pertenecientes a esta producción fue parcialmente presentado hace algunos años (MORENO y ALARCÓN, 1996a, 1285-1300).

${ }^{28}$ No se han localizado en el yacimiento de Cercadilla conjuntos que puedan fechar con suficiente precisión estos productos.
} 
En cuanto a las formas existentes en Cercadilla, están representados los tipos Hayes 23a, 23b, 181.1, 181.2, 182, 196 y 197, siendo especialmente numeroso el último. Resulta significativa la ausencia de cazuelas de los tipos Hayes 193 y $194^{29}$, posiblemente porque los originales africanos son cronológicamente anteriores al fenómeno de imitación aquí analizado.

Las formas más imitadas dentro de este grupo, y que incluso muestran cierta evolución ajena a los modelos originales, son las fuentes Hayes 181, las tapaderas Hayes 196 y las cazuelas Hayes 197. De la contrastación con las cronologías aplicadas a los modelos africanos se deduce que estas formas deben ser frecuentemente imitadas a partir de mediados del siglo II d.C., aunque sea en el tránsito con el siglo III d.C. cuando se alcance una mayor producción que ha de mantenerse durante la primera mitad de dicha centuria ${ }^{30}$.

Consideramos que el subtipo Hayes 23a (ATLANTE I, 1981, 217) debe ser uno de los que muestran el inicio de estas imitaciones a nivel cronológico, el escaso número de piezas localizadas así parece atestiguarlo. Los tipos Hayes 181 (ATLANTE I, 1981, 215) y 197 (IBID., 1981, 219) también aparecen en el siglo II d.C. por lo que puede pensarse que su imitación comenzara en dicha centuria.

A tenor de los datos analizados no parece que se imitara en Córdoba cerámica africana de cocina con anterioridad a mitad del siglo II d.C. Así parece indicarlo la ausencia de imitaciones de formas tan características de la facies flavia y antoniniana como las cazuelas Hayes 194 (ATLANTE I, 1981, 216) que sí aparecen en forma de productos africanos en el yacimiento, aunque en número muy escaso. No obstante, no descartamos que de forma esporádica puedan aparecer imitaciones de africana de cocina con anterioridad a la mitad del siglo II d.C.

\section{Imitaciones de terra sigillata africana}

Nos encontramos en Cercadilla con un grupo de piezas del máximo interés pues evidencian en su conjunto un ánimo por imitar sigillata africana de los tipos A, A/D y C. Estas imitaciones no son muy fieles en algunas piezas sino que parecen sólo inspirarse en determinados modelos africanos, este hecho provoca que su clasificación y sobre todo su parentesco con algún tipo africano sea ciertamente dificultosa.

\footnotetext{
${ }^{29}$ Tenemos constancia de la presencia de estos tipos de cazuelas africanas en Córdoba aunque en el caso de la forma Hayes 193 los datos están aún inéditos.

${ }^{30}$ No tenemos datos cronológicos fiables en los contextos de Cercadilla por lo que sólo podemos emplear lo conocido para los tipos base en africana de cocina.
} 
Hemos establecido tres grupos, siendo el más variado a nivel tipológico el de las imitaciones de africana $A$ representada por los tipos Hayes $3 c, 5 c, 6 b^{31}$, Hayes $9 b$, 14a, 14b, Hayes 15, 16, 14/17 y Hayes 17b var. El segundo grupo sería el de las posibles imitaciones de A/D, con los tipos: Hayes 27 y 31 .

No obstante, es más numeroso en ejemplares el grupo de imitaciones de africana C. Se han encontrado piezas que remedan los tipos Hayes $32 / 33,45,49^{32}$ y Hayes 50 , siendo especialmente numeroso el último.

A nivel cronológico -por los tipos imitados- da la impresión que sólo a partir del último cuarto del siglo II d.C. comenzarían, prácticamente a modo de ensayos, las imitaciones de formas de sigillata africana, sobre todo $\mathrm{A}^{2}$. No obstante será en el siglo III d.C. cuando se desarrollen en mayor número.

De los datos que se desprenden de la llegada de productos africanos a Córdoba se deduce que es la cerámica de cocina la que inicia estas importaciones a mediados del siglo II d.C. (CARRILLO y MURILLO, 1996, 1301-1319). Son estos productos y no la sigillata africana los que deben imitarse desde época más antigua. No obstante, el paulatino crecimiento de las importaciones de sigillata africana A debe animar de alguna manera a los talleres imitadores a aumentar su repertorio formal fabricando progresivamente también productos de mesa. Estos primeros momentos en la imitación de africana A deben situarse a finales del siglo II d.C.

Las primeras imitaciones de sigillata africana denotan su carácter de ensayo, ya que más que copiar la forma quizás fuera más propio hablar de inspiración. Posiblemente existieran en principio en estos alfareros béticos ciertas limitaciones técnicas que impidieran la elaboración de unos productos cuidados tanto en su aspecto formal como decorativo. Así, los barnices suelen tener un color muy rojizo con pequeñas motitas oscuras, mostrando un aspecto semibrillante y cubriente de cierta calidad.

Las decoraciones en estos materiales se reducen por ahora a escasos fragmentos en los que se insertan sencillas líneas de motivos a ruedecilla.

\section{Consideraciones Finales}

Tanto en Cercadilla como en el resto de Córdoba encontramos que los testimonios existentes hasta el momento sobre la cerámica de cocina itálica son muy escasos. Este

\footnotetext{
${ }^{31}$ Estos primeros tres tipos son ciertamente dudosos sobre todo el tipo Hayes 5c por la escasez y deficiente conservación de las piezas recuperadas.

${ }^{32}$ Estos tres tipos tampoco son definitivos, especialmente el último, ya que puede tratarse de alguna variante emparentada con la forma Hayes 181.
} 
hecho llama poderosamente la atención, pues extraña que no aparezcan en la capital de la Bética conjuntos de cocina itálicos de época augustea con cierta entidad. Posiblemente aún no se hayan localizado aunque su presencia debe ser relativamente abundante.

La presencia en Córdoba de la sigillata itálica parece temprana, con algunos productos centrados en el último tercio del siglo I a.C. Entre el 15 a.C. y el cambio de Era se constata una mayor variedad formal. Aunque se trata en su mayor parte de productos de Arezzo, se documentan también ejemplares que proceden de Pozzuoli o Roma (MARCOS, 1976, 95). Esta fase, que puede alargarse hasta finales del principado de Tiberio, constituye el momento álgido de las importaciones a Córdoba de sigillata itálica.

A partir del 40 d.C. se comprueba un descenso brusco de esta última familia cerámica por la competencia con la sigillata gálica, que comienza a aparecer en la Colonia Patricia procedente sobre todo de los talleres de la Graufesenque y Montans, y en menor medida, de otros como Saint-Romain-en Gal.

La llegada a Córdoba de estos productos tiene su inicio, grosso modo, en época de Claudio, aunque su auge debe coincidir con la llegada masiva de productos de La Graufesenque durante época de Nerón y los primeros emperadores de la dinastía flavia. A partir de este momento los productos hispánicos, sobre todo del taller de Andújar, que venían llegando con anterioridad, representan ya una fuerte competencia a la sigillata gálica, acaparando paulatinamente el mercado de la Colonia Patricia.

El inicio del flujo de sigillata de Andújar debe ser relativamente temprano, como demuestra la presencia de la marca MSM, con producción centrada en época de Claudio (ROCA, 1981, 407). Son momentos de tanteo, con llegadas muy esporádicas, en los que compite con los productos galos. No obstante, les ganarán la partida a partir de época flavia. Los porcentajes de sigillata de Andújar habrán de ser mayoritarios durante la primera mitad del siglo II d.C. para llegar, aún en proporciones elevadas, al tercer cuarto de dicha centuria, sufriendo en estos momentos la competencia de la sigillata africana de mesa (CARRILLO y MURILLO, 1996, 1316-1317). No se ha constatado la presencia clara de productos de otros talleres béticos, aunque es posible que llegaran en algún caso.

En cuanto a los productos de los talleres riojanos, son poco frecuentes en Cercadilla y coinciden con aquellos momentos en los que aún no están bien definidas las redes comerciales propias de la sigillata de Andújar (mediados del siglo I d.C.).

Un fenómeno muy interesante es el de las imitaciones de cerámica importada de cocina y de mesa. Es el caso de la cerámica de barniz rojo tipo Peñaflor, que nosotros preferimos denominar Imitaciones béticas de cerámica importada de cocina y mesa. 
Grupo altoimperial, ya que a nuestro juicio forman parte de un fenómeno unitario, muy amplio en el tiempo, cuyo hilo conductor es la remedación o imitación ${ }^{33}$, tanto técnica como formal, de modelos exógenos ${ }^{34}$.

En este sentido, el repertorio formal de esta cerámica es más amplio en Córdoba que las tipologías conocidas hasta el momento, por lo que no sería extraño que existiera en el entorno de la ciudad algún alfar que fabricara estos productos, así parece intuirse de la presencia en Cercadilla de varios fragmentos del que hemos denominado tipo V. La cronología de esta vajilla se extiende desde época augustea hasta la mitad del s. I d.C. A partir de este momento no sabemos si los restos que aparecen son residuales.

En una de las tumbas encontradas en el solar de la antigua fábrica de La Constancia se encontraron nueve piezas de estas imitaciones altoimperiales, tres páteras, tres cuencos y tres vasitos. Parece claro que estamos ante tres servicios compuestos cada uno por un vaso y un cuenco del tipo Ic y un plato de la forma IIc (RUIZ, 1996, 184).

El otro gran grupo de sigillata, en este caso bajoimperial, aparece constituido por las producciones africanas. La convivencia de cerámica de cocina importada y africana A con la última facies de la terra sigillata hispánica de Andújar, documentada en uno de los vertederos de Orive (CARRILLO y MURILLO, 1996, 1307), nos proporciona una valiosa idea de los momentos iniciales de la llegada de estos productos a la Colonia Patricia y de la competencia que supone para los productos procedentes de Isturgi. La existencia en Cercadilla de una cazuela Hayes 194, fechable en el siglo I d.C., permite rebajar algo más el inicio -quizás en forma de ensayo- de la importación de estos productos. No obstante, su llegada sólo será masiva a partir de mediados del siglo II d.C., siendo algo más tardía la de los productos de mesa (ALONSO de la SIERRA, 1995, 158).

A partir de este momento comienza un complicado panorama en el que van llegando a Córdoba de forma paulatina la práctica totalidad de producciones y subproducciones de la sigillata africana, combinándose este hecho con la sucesiva imitación de muchas de estas importaciones ${ }^{35}$.

\footnotetext{
${ }^{33}$ Esta acepción de imitación es la más común en arqueología (RISUEÑO y ADROHER, 1990, 385). Se trataría en buena medida de la respuesta de los alfareros regionales ante el estímulo provocado por la renovación en los gustos por una determinada vajilla.

${ }^{34}$ Para que una imitación pueda considerarse como tal, debe coincidir en ella dos características, la primera es que cronológicamente debe ser algo posterior al producto imitado y la segunda es que ha de presentar algunas de las características formales y técnicas que definen a éste (RISUEÑO y ADROHER, 1990, 382).

${ }^{35}$ El mayor dinamismo formal de la vajilla africana frente a la de sigillata clásica debió provocar una más rápida adecuación formal a los modelos exógenos y un proceso de adaptación de los alfareros regionales a los nuevos gustos.
} 
En la Colonia Patricia pueden constatarse dos momentos álgidos de la sigillata africana durante los siglos II y III d.C. El primero se produce en la segunda mitad del siglo II d.C., en que destaca la presencia de africana A del tipo Hayes 9 (CARRILLO y MURILLO, 1996, 1308), mientras que el segundo tiene lugar a mediados del siglo III d.C., con abundancia de africana C de la forma Hayes 50 (ALONSO de la SIERRA, 1995, 159). Entre estos dos momentos álgidos encontramos algunas piezas que en cierta manera "rellenan" este impás y que pertenecen a la subproducción $\mathrm{A}^{2}$ y a la producción $\mathrm{A} / \mathrm{D}$.

El segundo gran conjunto de imitaciones documentado en Cercadilla es el de africana de cocina y mesa, y que para no desconectarlo del grupo altoimperial preferimos denominar: Imitaciones béticas ${ }^{36}$ de cerámica importada de cocina y mesa. Grupo bajoimperial.

Como veíamos con anterioridad las importaciones de cerámica africana se inician en Córdoba con los productos de cocina a mediados del siglo II d.C. (CARRILLO y MURILLO, 1996, 1301-1319). De un modo similar comienzan en Córdoba sus imitaciones en un momento poco posterior a los comedios del siglo II d.C. No obstante, el crecimiento progresivo de las importaciones de sigillata africana debe obligar a los talleres a aumentar su repertorio formal, iniciando la fabricación de productos de mesa de manera experimental a finales del siglo II d. $\mathrm{C}^{37}$.

Estas producciones continúan a lo largo del siglo III d.C. imitando ya productos en C. El siglo IV d.C. debe ser un momento intermedio que conecta ${ }^{38}$ esta producción con la denominada terra sigillata hispánica tardía meridional (MORENO y ALARCÓN, 1996b, 94), muy abundante en Córdoba durante la primera mitad del siglo V d.C. Asociado a la TSHTM aparece con asiduidad cerámica de cocina de aspecto muy tosco, que en la Colonia Patricia puede tener carácter de imitación de productos importados (MORENO y ALARCÓN, 1996b, 108). De confirmarse este hecho en ambos casos, cabría aplicar la continuidad del término anterior, denominándose a ambas: Imitaciones béticas de cerámica importada de cocina y mesa. Grupo tardorromano.

\footnotetext{
${ }^{36}$ En la propia Córdoba ha sido localizado recientemente un vertedero de alfar con defectos de cocción de imitaciones de africana de cocina y mesa que demuestra el carácter local de estas imitaciones en la Colonia Patricia.

${ }^{37}$ Parece intuirse que dentro de las imitaciones locales de africana de mesa, al inicio en forma de tanteo de la imitación de formas abiertas tempranas, sucede un momento más sólido en la imitación de formas abiertas tardías y africana A/D. No deja de ser llamativo que el ritmo en la importación de africana de mesa en Córdoba es justo el contrario. Nos encontraríamos así con una alternancia sucesiva durante el siglo II d.C., e incluso el siglo III d. C., de momentos álgidos en la importación y momentos álgidos en la imitación.

${ }^{38}$ Esta conexión aún no ha sido constatada de manera fehaciente, no obstante existen similitudes entre ambos grupos demostrada en piezas que a pesar de ser productos de mesa incorporan tratamientos de borde ceniciento propios de la cerámica de cocina. Otro detalle de interés es la existencia de piezas decoradas a ruedecilla en las imitaciones de africana, siendo ésta una de las características más frecuentes de la TSHTM.
} 
En resumen, y a modo de esquema, el fenómeno de las imitaciones se estructuraría en Córdoba de la siguiente manera: Durante los siglos I y primera mitad del II d.C. se centraría la producción del grupo de imitaciones béticas altoimperiales de cocina que sigue el modelo de una variante tardía de las fuentes con barniz rojo pompeyano (MARTÍNEZ RODRÍGUEZ, 1989, 60)-, y la fabricación del grupo de imitaciones béticas altoimperiales de mesa -que imitan determinados tipos de sigillata itálica y en algún caso paredes finas (IBID., 1989, 60)-. Para ambos se establecen talleres de forma hipotética en Peñaflor (Sevilla) (IBID., 1989, 64), Andújar (Jaén) (IBID., 1989, 61) y Córdoba (vid. supra).

Durante la segunda mitad del siglo II, todo el siglo III y perduraciones por contrastar en el siglo IV, se elabora el grupo de imitaciones béticas bajoimperiales de cocina, que reproduce formas de la vajilla africana. Los talleres en este caso están constatados en Córdoba (vid. supra), Marchena (Sevilla) (ROMERO, 1987, 886), Matagallares (Almuñécar) (BERNAL y NAVAS, 1996, 50) y Alcalá del Río (Sevi1la) (SÁNCHEZ, 1995, 267). A partir de finales del siglo II d.C. comienzan a fabricarse las imitaciones béticas bajoimperiales de mesa, que se emparentan formalmente con la sigillata africana A,A/D y C. El único alfar localizado hasta el momento en la Bética es el de Córdoba.

Durante los siglos IV-V d.C., con perduraciones en el siglo VI, tendríamos las posibles imitaciones béticas tardorromanas de cocina, que remedan cazuelas y ollas de cerámica grosera importada (MORENO y ALARCÓN, 1996b, 108). Se desconocen en la Bética la existencia de alfares para estos productos. Por último, nos encontramos con las imitaciones béticas tardorromanas de mesa, que habría que poner en relación principalmente con la sigillata africana D (formas 3,4,9..) (ORFILA, 1995, 200). Tampoco en este caso se conocen alfares.

\section{BIBLIOGRAFIA}

AA.VV. (1983): "T.S.H. Terra sigillata hispánica”, Monografías del Museo Arqueológico Nacional $\mathrm{n}^{\circ} 2$. Madrid.

AA.VV. (1995): Ceràmica comuna romana d'època Alto-Imperial a la Peninsula Ibèrica. Estat de la questió, Monografíes Emporitanes VIII. Ampurias.

AGUAROD, M.C. (1991): Cerámica romana importada de cocina en la Tarraconense. Zaragoza.

ALONSO DE LA SIERRA, J. (1995): “Cerámicas africanas de Córdoba”, Anales de Arqueología Cordobesa, 6, 145-173. 
ARQUEOLOGIA URBANA (1991): Catálogo de la exposición, Córdoba.

ATLANTE DELLE FORME CERAMICHE I (Medio e tardo impero) (1981): Enciclopedia dell'Arte Antica. Roma.

ATLANTE DELLE FORME CERAMICHE II (Tardo ellenismo e primo impero) (1985): Enciclopedia dell 'Arte Antica. Roma.

BALIL, A. (1978): "Notas de cerámica romana (II)", Boletín del Seminario de Estudios de Arte y Arqueología, XLIV, 403-416.

BELTRAN LLORIS, M. (1990): Guía de la cerámica romana. Zaragoza.

BERNAL, D. y NAVAS, J. (1996): "Los Matagallares: Un centro alfarero romano en Salobreña”, Revista de Arqueología, 182, 42-51.

CARRILLO, J.R. y MURILLO, J.F. (1996): "Un vertedero con cerámica africana de cocina en Colonia Patricia", Atti del XI Convegno Intenazionale di studio sul L'Africa Romana, 1301-1319.

CONSPECTUS FORMARUM TERRAE SIGILLATA ITALICO MODO CONFECTAE (1990). Bonn.

D.A.F. (1986): La terre sigillée gallo-romaine, Documents d'Archeólogie Française, 6. París.

FERNANDEZ GARCIA, Ma. I. (1986): "Repertorio temático de la Terra Sigillata Hispánica decorada de los Villares de Andújar (Jaén)", Cuadernos de Prehistoria de la Universidad de Granada, 11, 355-389.

GARCIA y BELLIDO, A. (1970): «Los hallazgos cerámicos del área del templo romano de Córdoba», Anejos de Archivo Español de Arqueología V.

HAYES, J.W. (1972): Late Roman Pottery, Londres.

HIDALGO, R. y MORENO, M. (1996): "La villa suburbana de Cercadilla", en Córdoba en tiempo de Séneca (Vaquerizo ed.), 122-123.

JIMENEZ, J.L. (1996): "El templo romano de la calle Claudio Marcelo en Córdoba: aspectos cronológicos, urbanísticos y funcionales" en LEON, P. (Ed.): Coloquio Internacional Colonia Patricia Corduba. Una reflexión arqueológica, 129-153, Córdoba, 1993.

JIMENEZ, J.L., RUIZ, D. y MORENO, M. (1996): "Nuevos avances en el conocimiento sobre el urbanismo de Colonia Patricia Corduba en el sector ocupado por el templo romano", Anales de Arqueología Cordobesa, 7, 115-140. 
MARCOS, A. (1976): "Estampillas de ceramistas sobre tazas aretinas Haltern 8 recogidas sin control arqueológico en el yacimiento del exconvento de la Merced de Córdoba", Corduba 2, 55-97.

MARTINEZ RODRIGUEZ, F. (1989): "Las cerámicas béticas de imitación tipo Peñaflor: bases para el estudio de un nuevo grupo cerámico de época altoimperial", Boletín de la Asociación Española de Amigos de la Arqueología 26, 60-65.

MORENO, M. y ALARCON, F.J. (1996a): "Producciones cerámicas locales o regionales de época tardía en Colonia Patricia Corduba. El yacimiento de Cercadilla", XI Convegno Internazionale di studio sul L'Africa Romana, Túnez, 1285-1300.

MORENO, M. y ALARCON, F.J. (1996b): "Materiales de época romana. La cerámica" en: El criptopórtico de Cercadilla. Análisis arquitectónico y secuencia estratigráfica, Sevilla 69-110.

MORENO ALMENARA, M. (1997): La villa suburbana de Cercadilla (Córdoba). Análisis arqueológico, Sevilla.

ORFILA, M. (1995): “¿Producciones de sigillata no clásica en la Bética? Las llamadas sigillatas paleocristianas de Cástulo", IV Reunió D'A rqueologia cristiana hispànica (Lisboa, 1992), 193-202.

OSWALD, F. (1931): Index of potters' stamps on Terra Sigillata, London.

OXÉ, A. y COMFORT, H. (1968): Corpus Vasorum Aretinorum, Bonn.

RISUEÑO, B. y ADROHER, A. M" (1990): "La cerámica de importación en el registro arqueológico", Florentia Iliberritana 1, 373-387.

ROCA, M. (1976): Sigillata hispánica producida en Andújar, Instituto de Estudios Giennenses, Excma. Diputación Provincial. Jaén.

ROCA, M. (1981): "Terra Sigillata Hispánica: Una aproximación al estado de la cuestión", Cuadernos de Prehistoria de la Universidad de Granada, 6, 385-410.

ROCA, M. (1982): "Breve introducción al estudio de la sigillata", Cuadernos de Prehistoria de la Universidad de Granada, 7, 359-404.

ROMERO MORAGAS, C. (1987): “Un horno de cerámica común romana en Marchena (Sevilla)", XVIII Congreso Nacional de Arqueología. Zaragoza, 863-872.

RUIZ NIETO, E. (1996): "Conjunto funerario de "La Constacia" (Necrópolis septentrional)", en Córdoba en tiempo de Séneca (Vaquerizo ed.), 182-185.

SANCHEZ SANCHEZ, $M^{a}$ A. (1995): "Producciones importadas en la vajilla culinaria romana del Bajo Guadalquivir", Cerámica comuna romana d'êpoca Alto-Im- 
perial a la Peninsula Ibérica. Estat de la qüestió, Monografíes Emporitanes VIII, 251-280.

SANTOS GENER, S. (1955): Memoria de las excavaciones del Plan Nacional realizadas en Córdoba (1948-1950). Informes y Memorias de la Comisaría General de Excavaciones Arqueológicas 31. Madrid.

SERRANO, E. (1983): "En torno a la difusión peninsular de la sigillata producida en Andújar", Rivista di Studi Liguri, XLVI, 65-81.

SOTOMAYOR, M. (1972): “Andújar, centro de producción y exportación de sigillata a Mauritania", Noticiario Arqueológico Hispánico 1, 263-304.

SOTOMAYOR, M. (1977): Marcas y estilos de la sigillata decorada de Andújar. Jaén.

SOTOMAYOR, M., PEREZ, A. y ROCA, M. (1976): "Los alfares romanos de Andújar (Jaén). Dos nuevas campañas", Noticiario Arqueológico Hispánico, 4, 111-147.

VENTURA, A. (1996): El abastecimiento de agua a la Córdoba romana II. Acueductos, ciclo de distribución y urbanismo. Córdoba. 

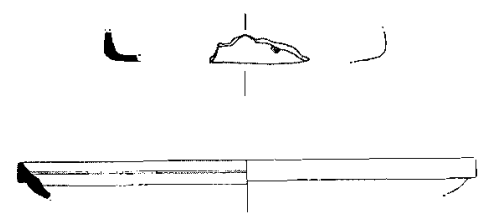

L......
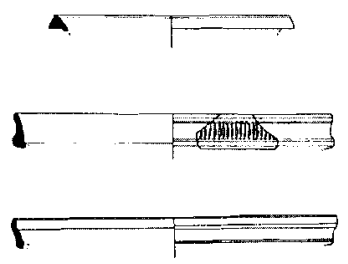
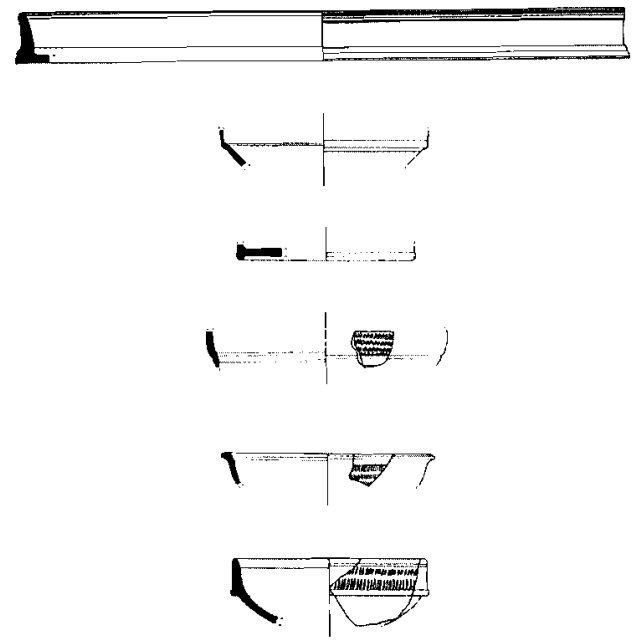

Fig. 1: Tipología de la Terra Sigillata itálica en Cercadilla
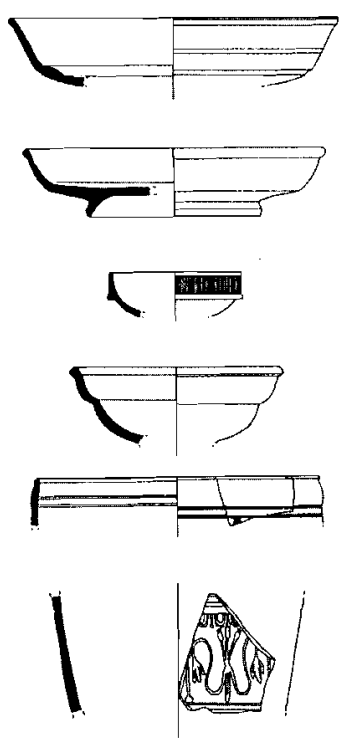
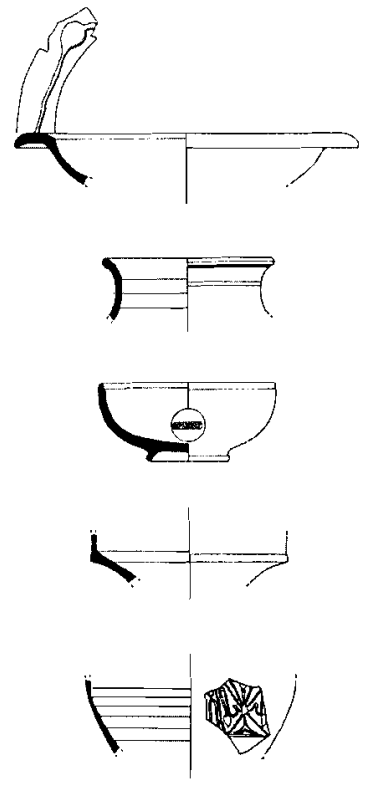

Fig. 2: Tipología de la Terra Sigillata gálica en Cercadilla 

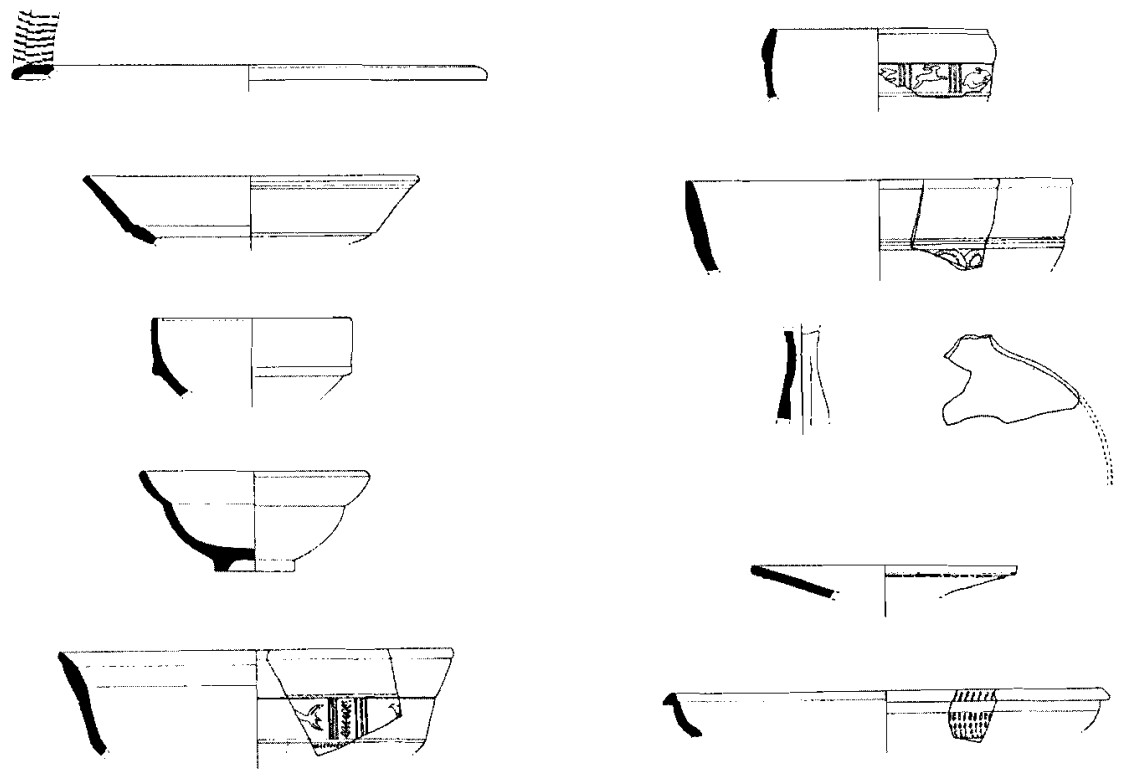

Fig. 3: Tipología de la Terra Sigillata hispánica en Cercadilla
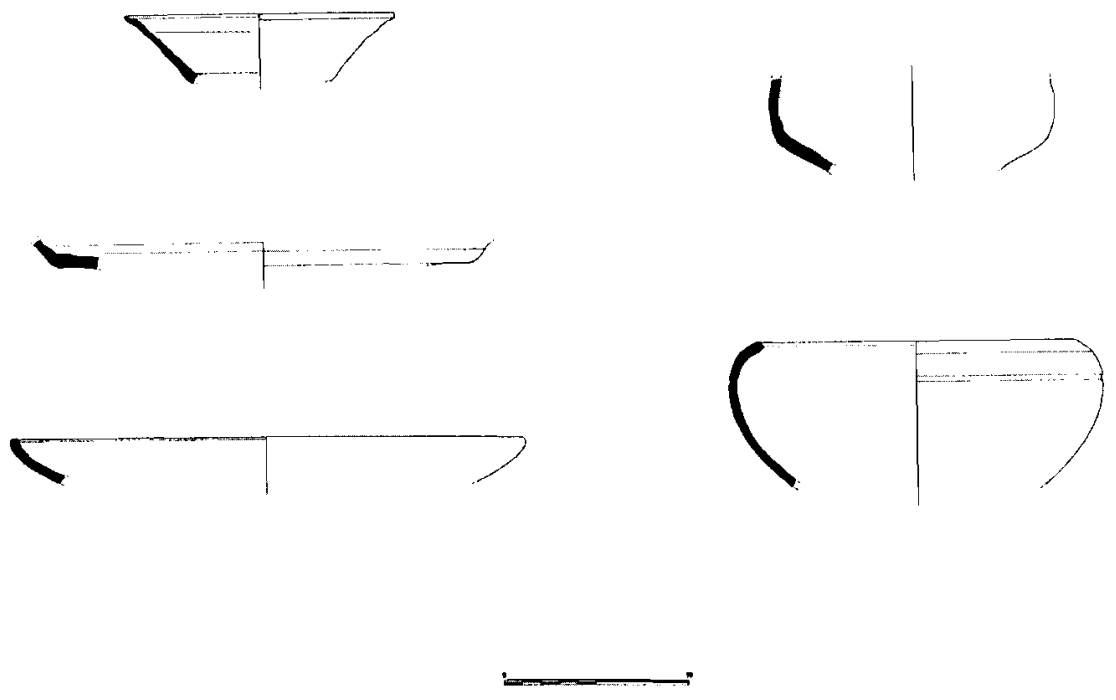

Fig. 4: Tipología del Barniz rojo tipo Peñaflor en Cercadilla 

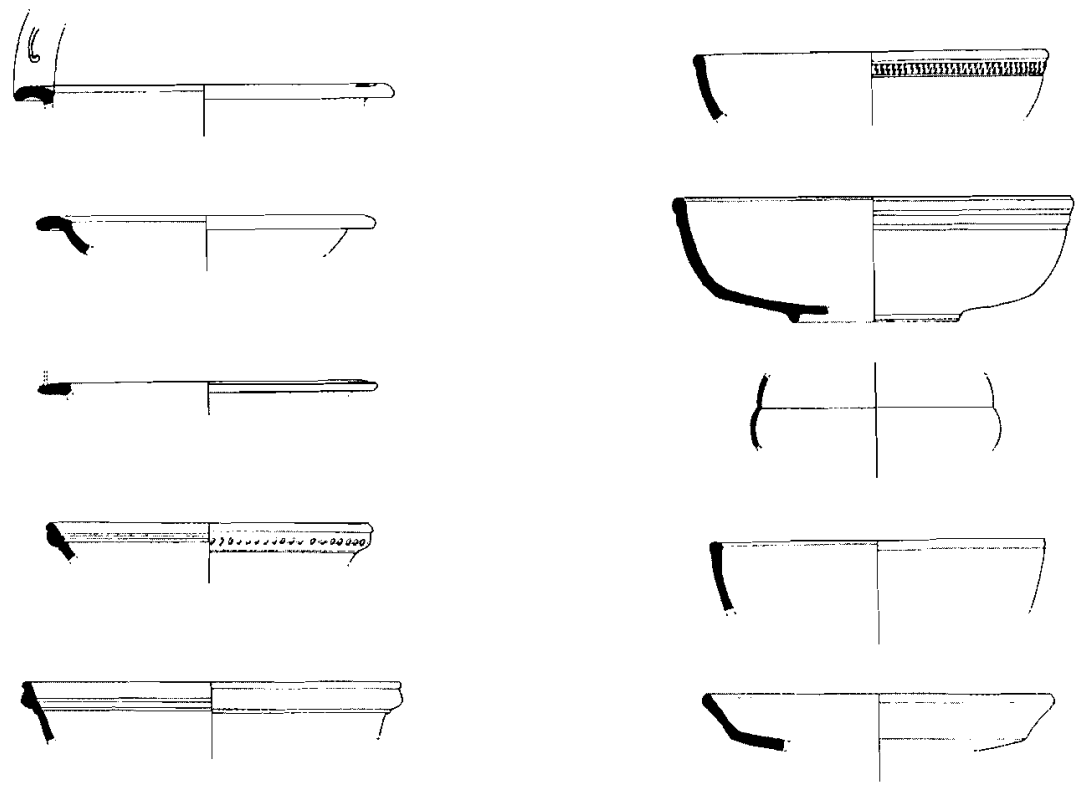

Fig. 5: Tipología de la Terra Sigillata africana A en Cercadilla
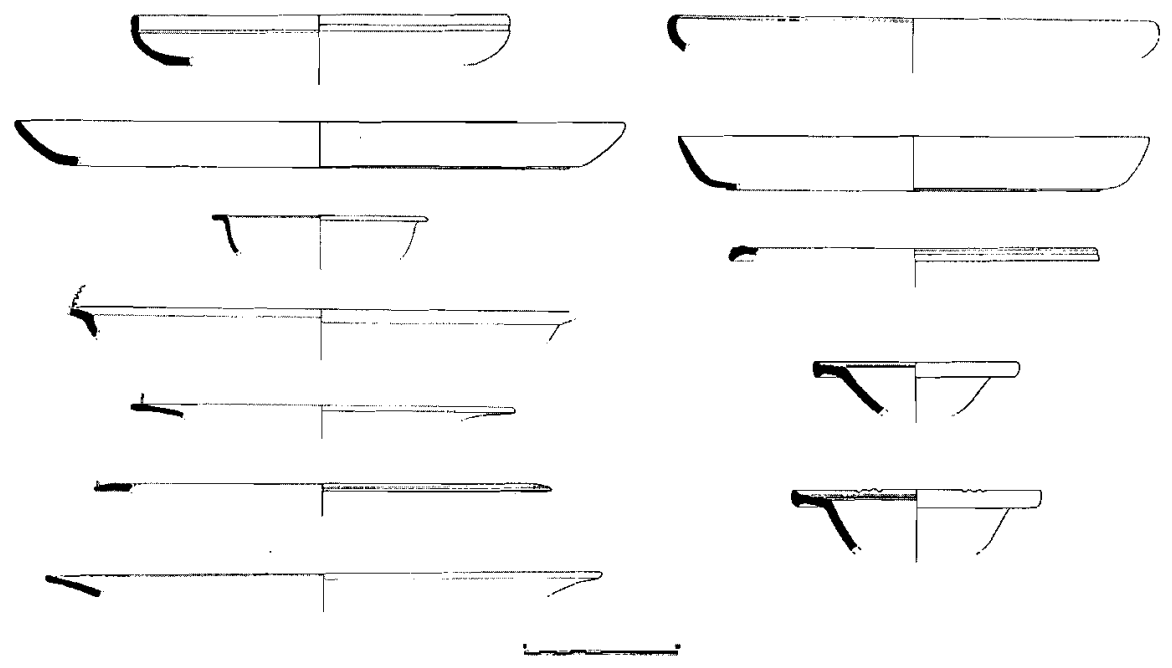

Fig. 6: Tipología de la Terra Sigillata africana A/D y C en Cercadilla 

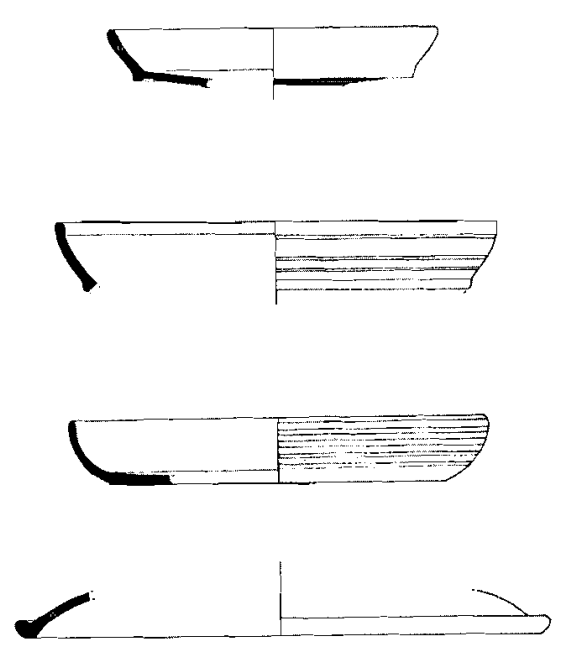

Fig. 7: Tipología de la cerámica africana de cocina en Cercadilla
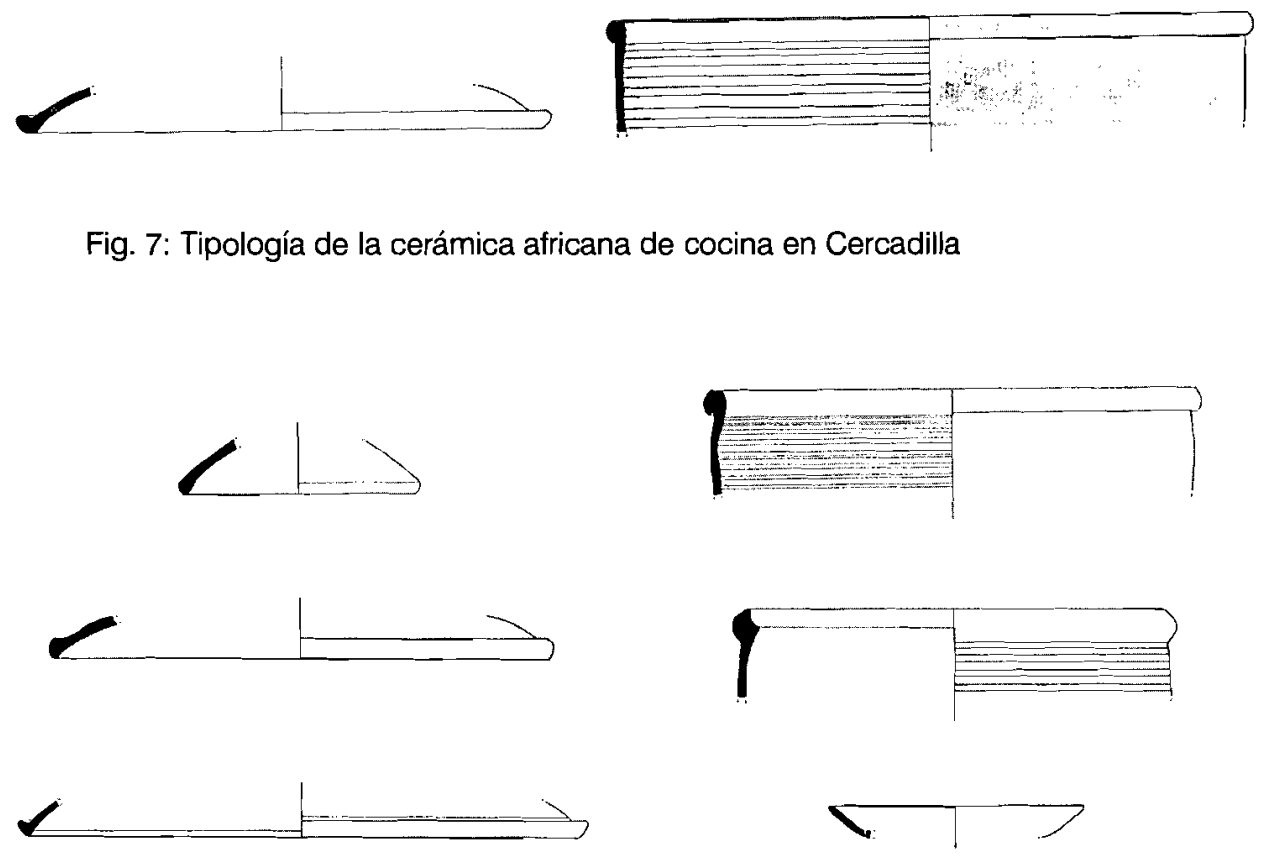
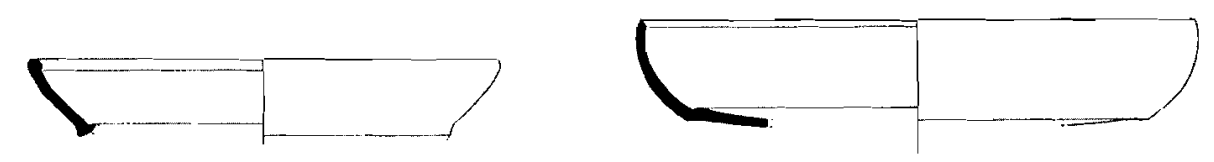

Fig. 8: Tipología de las imitaciones de africana de cocina en Cercadilla 

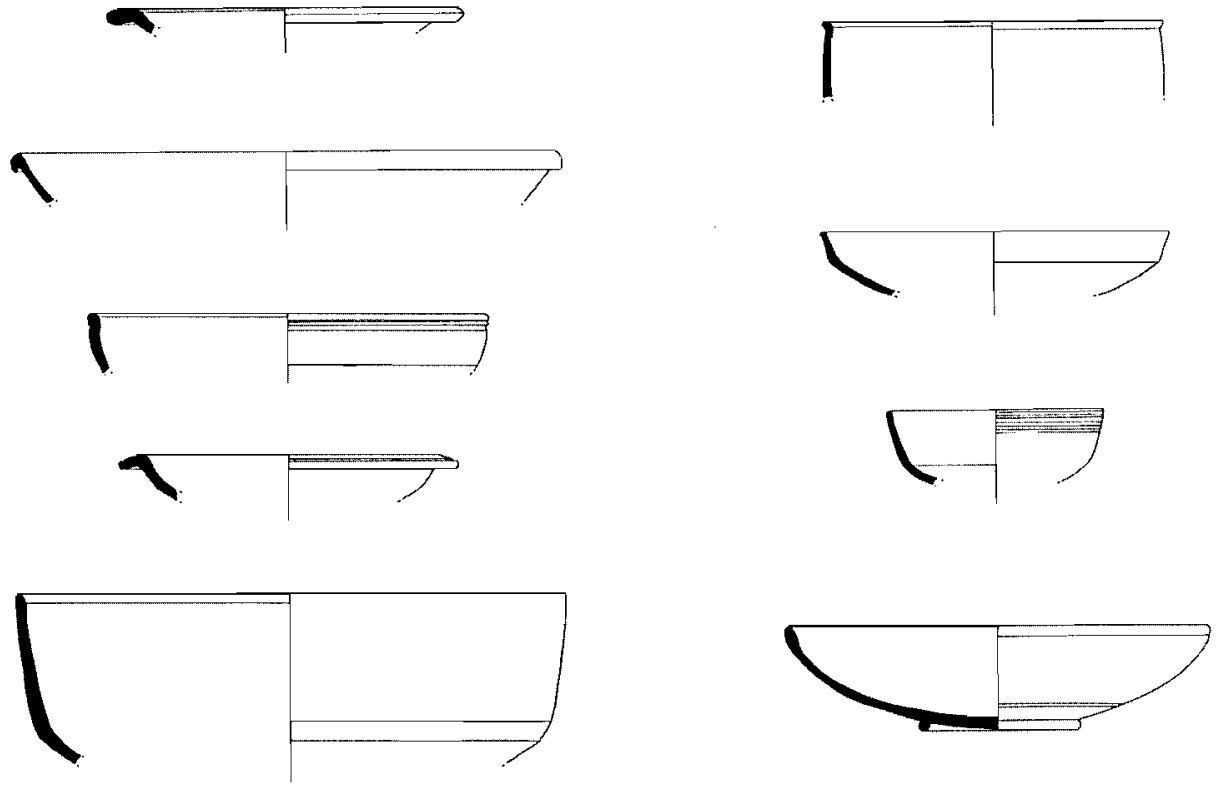

Fig. 9: Tipología de las imitaciones de Terra Sigillata africana A
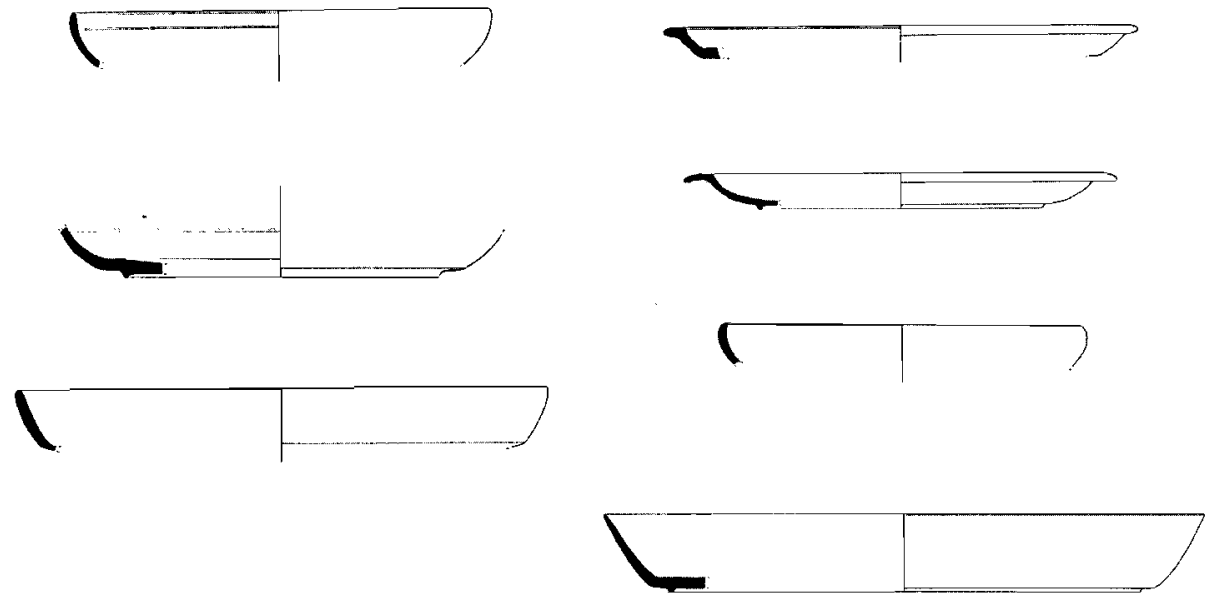

Fig. 10: Tipología de las imitaciones de Terra Sigillata africana A/D y C 